\title{
A Study on the Structural Relationship among Customer Experience, Emotional Response, Customer Value and Customer Satisfaction of Traditional Teahouse Users
}

\section{전통찻집 이용자의 고객경험, 정서적 반응, 고객가치 및 고객만족의 구조관계 연구}

\author{
Hyun-Ah Song ${ }^{1}$, Chae-Kwan Lim² \\ 송현아 ${ }^{1}$, 임채관 2 \\ ${ }^{1}$ Graduate Student, Department of Business Administration, Tongmyong University, Korea, \\ sha0071@hanmail.net \\ ${ }^{2}$ Professor, Department of Distribution Management, Tongmyong University, Korea, cklim@tu.ac.kr \\ Corresponding author: Chae-Kwan Lim
}

\begin{abstract}
The purpose of this study was to examine the relationship among emotional response and customer value and customer satisfaction to use by measuring customer experience in traditional teahouses. The survey for empirical analysis was conducted for three months from February to April 2019 for those who have used traditional tea houses living in Busan Metropolitan City. A total of 350 copies of the questionnaire were distributed, of which 296 copies were used for analysis. The SPSS was used to verify the demographic characteristics and reliability and validity of measurement tools of data collected by conducting surveys. In addition, convergent feasibility and discriminative feasibility were verified using AMOS, and structural equation model analysis was conducted for hypothesis verification of this study. The results of this empirical study are summarized as follows. First, for hypothesis 1 and hypothesis2 stasting that customer experience of traditional teahouse will affect emotional response and customer value. As a result, customer experience (intellectual, behavioral, emotional, and sensual) respectively. Second, the hypothesis 3 that the emotional reaction to the traditional teahouse will affect the customer's value, the emotional response in the traditional teahouse has a positive effect on the customer value. Third, empirical responses were found to have a positive effect on customer satisfaction as a result of examining Hypothesis4 that emotional response would affect customer satisfaction. Fourth, we tested hypothesis5 that customer value would affect customer satisfaction. This result can be interpreted as the result that customer satisfaction level of traditional teahouse is higher as the customer value level of customer is higher.
\end{abstract}

Keywords: Traditional Teahouse, Customer Experience, Emotional Response, Customer Value, Customer Satisfaction

요약: 본 연구는 전통찻집 이용자를 대상으로 고객경험을 측정하여 정서적 반응과 고객가치, 고객만족에 미치는 영향관계를 검증하고자 하는데 목적이 있다. 이를 위해 전통찻집에서의 고객경험을 4 가지 하위차원(지적, 행동적, 정서적, 감각적 경험)으로 규명하고, 이들이 정서적

Received: September 17, 2021; $1^{\text {st }}$ Review Result: November 2, 2021; $2^{\text {nd }}$ Review Result: December 21, 2021 Accepted: January 29, 2022 
반응, 고객가치, 고객만족 등에 미치는 영향관계를 설문조사를 통해 실증적으로 검증하였다. 실증분석을 위한 설문조사는 부산광역시에 거주자 중 전통찻집 이용 경험자를 대상으로 2019년 2월부터 4월까지 3개월간 실시하였다. 설문지는 총 350 부를 배부하였으며, 그 중 296부의 유효 설문을 분석에 활용하였다. 조사를 통해 수집된 데이터의 일반 현황과 측정 도구의 신뢰성과 타당성을 검증하기 위하여 $\mathrm{SPSS}$ 를 이용하였으며, 또한 집중타당도와 판별타당도를 검증하고 나아가 본 연구의 가설검증을 위하여 $\mathrm{AMOS}$ 를 이용하여 구조방정식 모형분석을 실시하였다. 연구결과를 요약하면 다음과 같다. 첫째, 전통찻집의 고객경험이 정서적 반응과 고객가치에 영향을 미칠 것이라는 가설 1 과 가설 2 의 검증결과 전통찻집의 고객경험(지적, 행동적, 정서적, 감각적)이 정서적 반응 및 고객가치에 유의한 영향을 미치는 것으로 나타났다. 둘째, 전통찻집에 대한 정서적 반응은 고객가치에 영향을 미칠 것이라는 가설3을 검증한 결과 전통찻집에서의 정서적 반응은 고객가치에 유의한 영향을 미치는 것으로 분석되었다. 셋째, 정서적 반응은 고객만족에 영향을 미칠 것이라는 가설4를 검증한 결과 정서적 반응은 고객만족에 유의한 영향을 미치는 것으로 분석되었다. 넷째, 고객가치가 고객만족에 영향을 미칠 것이라는 가설5를 검증한 결과 유의한 영향 관계를 확인하였다. 이러한 결과는 구성요인들의 상대적 중요성 등을 확인함으로서 향후 전통찻집의 활성화에 있어 실무적인 가능성을 확인했다는데 그 의의가 크다고 하겠다.

핵심어: 전통찻집, 고객경험, 정서적 반응, 고객가치, 고객만족

\section{1. 서론}

최근 들어 웰빙 바람을 타고 사회 전반적으로 차문화에 대한 인식과 관심이 확대되면서 차문화를 발전, 성장시키기 위해 여러 시, 군, 차인 단체에서 우리의 전통차를 알리고 문화인식을 고양시키려는 노력이 지속되고 있다. 그동안의 전통적인 분위기와는 다른 새로운 트렌드의 차문화 공간들이 생겨나고 생활주변 곳곳에서 차문화 강좌를 비롯한 차(茶)축제와 체험다례 등 차와 관련된 많은 행사들이 펼쳐지고 있다. 또한 좋은 품질의 찻잎으로 가공된 차 제품을 선보이며 젊은 층을 겨냥한 새로운 형태의 전통찻집들도 생겨나고 있다. 즉, 현대적 분위기에 고품질의 차종과 다양한 소비자의 욕구에 반응하는 새로운 전통찻집들은 고루한 전통찻집의 형태를 벗어나 깔끔하고 세련된 현대적 실내공간으로 특히 젊은 층의 공감을 불러일으키고 있다. 그럼에도 불구하고 중국이나 일본에 비해 우리 차문화는 보편적으로 대중화되지 못하고 제자리에 머물러 있는 실정이며, 관련 연구 또한 커피나 다른 음료에 비해 부족한 실정이다.

이러한 관점에서 본 연구는 최근의 차에 대한 새로운 수요와 시대적 추세를 반영하고 전통찻집의 새로운 가치를 창출하고 이를 확산하기 위한 목적으로 시작하였다. 즉, 본 연구는 전통찻집의 이용 고객들을 대상으로 고객경험의 특성이 전통찻집을 이용하는 과정에서 지각하게 되는 정서적 반응과 고객가치 나아가 고객만족에 미치는 영향관계를 실증적으로 규명하고자 하는 것이다. 이를 위하여 본 연구에서는 고객경험의 하위차원을 감각적, 지적, 행동적, 정서적 경험 차원으로 구분하여 이들 경험요인과 정서적 반응, 고객가치 및 고객만족 간의 구조관계를 실증적으로 규명함으로써 전통찻집의 활성화에 대한 가능성과 향후 전통찻집을 운영하고자 하는 희망자에게 실무적 도움이 될 수 있는 기초 정보를 제공하고자 한다. 


\section{2. 이론적 배경}

\section{1 전통차와 차문화}

차는 차 잎을 어떻게 가공하느냐에 따라 발효 정도나 채취 시기, 가공 방법, 색상 등 분류 방법이 다양하게 나누어지며, 오래전부터 약용이나 음료로 시작되어 한국의 긴 역사를 함께 해오면서 국가 의식, 종교적인 행사, 사상적인 생활철학 등으로 우리의 소중한 전통문화 유산으로 발전해 왔다[1]. 한편 차문화의 의미는 문화의 큰 범주 내에서 차와 연관된 여러 형태의 규범 및 내용이라 할 수 있다. 이러한 차문화의 범주는 광범위한 것으로 다도, 다례, 차의 역사뿐만 아니라 현대의 차 산업, 제다, 차 음식, 다구, 식물학, 차의 의학적 효능, 차 교육, 전통찻집 등 차와 관련한 사회의 모든 분야를 포함한다[2][3]. 또한 차문화는 우리 민족이나 국가의 특징을 잘 드러내는 정체성, 대표성 등을 가지고 있어 다른 민족이나 그 나라의 문화와 구별되는 고유성과 창의성을 나타내주는 문화유산이며, 민족문화로서 차문화의 역사를 함께 해오고 있다[1].

\section{2 고객경험}

고객경험은 고객이 기업이나 브랜드를 직접 또는 간접적으로 접할 때의 주관적이고 내부적인 반응이며 조직과 고객 간의 상호작용에 의해 일어난다[4]. 이는 고객경험이 물리적인 수행에서 느껴지는 자극과 고객의 기대에 반하여 주관적으로 측정되는 혼합적인 감정이라고 보는 것이다. 고객경험은 고객에게 단순한 즐거운 경험을 제공하는 데에 그치지 않고 고객의 긍정적 반응과 만족을 끌어내는 중요한 요소가 되며, 고객경험은 소비자의 감정반응을 야기하며 이는 고객의 행동의도를 예측할 수 있는 요소가 된다[5]. 본 연구에서는 전통차와 차문화에 대한 고객경험을 차와 차를 매개로 하여 고객이 가상 혹은 사건의 직접적 관찰이나 참여로 인해 일어나는 자극에 대한 반응으로 정의하고, Brakus et al.(2009) 및 Zarantonello \& Schmitt(2010) 등이 제시한 경험의 하위변수인 감각적 경험, 지적 경험, 정서적 경험, 행동적 경험 차원으로 구성하고 이를 선행요인으로 활용하였다[6][7].

\section{3 정서적 반응}

정서(affect)란 감정과 사람, 사물, 사건 등의 어떤 대상에 대하여 느끼는 폭 넓은 범위의 느낌을 총칭하는 용어로 감정과 기분을 포괄하는 개념이다. Plutchik(1980)는 감정이란 자극물에 대한 반응들의 복잡한 연속으로서 인지적 평가, 주관적 변화, 자율 및 신경적 각성, 행동하려는 충동, 그 자극물에 대해 영향을 미치는 행동을 포함하는 개념이라고 정의하였다[8]. 정서적 반응은 소비자가 설득메시지에 노출되었을 때 생기는 주관적인 느낌을 뜻한다[9]. 인지적 반응이 설득메시지의 주체가 되는 제품 등에 대해 자연스럽게 생성되는 생각의 집합인 반면 정서적 반응은 설득 메시지를 접했을 때 무의식적으로 떠오르는 즐거움, 두려움과 같은 감정의 보고(寶庫)라 할 수 있다[10]. 본 연구에서는 전통찻집에 대한 정서적 반응을 전통차와 차문화를 경험한 고객의 마음속에서 일어나는 즐거움, 좋고 싫음의 주관적 감정 상태로 정의하고자 한다. 


\section{4 고객가치}

고객가치는 1990 년대 들어 마케팅 연구자와 실무자들 사이에서 관심이 증대되기 시작하였다[11]. Bojanic(1996)은 고객가치를 다양한 가치형태로 나타나는 지각된 가치라고 정의하면서 가치형태를 동등한 가격에 동등한 품질을 제공하는 것, 프리미엄 가격에 우수한 품질을 제공하는 것, 그리고 할인 가격에 낮은 수준의 품질을 제공하는 것 등 3 가지로 개념화하였다[12]. Woodruff(1997)는 고객가치를 제품속성, 성과, 그리고 고객의 사용상황에서 목적과 의도를 달성하기 위해 조정되는 결과에 대한 고객의 지각된 선호와 평가로 정의하고 있다[13]. Zeithaml(1988)은 고객가치를 고객이 제공한 모든 것과 제공받은 모든 것에 기초한 상품의 효용에 대한 고객의 전반적인 평가라고 제시하였다[14]. 본 연구에서는 고객가치를 고객이 전통찻집에서 경험한 후 모든 과정에서 제공된 서비스나 편익에 기초하여, 고객이 느끼는 전반적인 평가로 정의하고자 한다.

\section{5 고객만족}

고객만족이란 대체로 개인이 느끼는 기대감이나 욕구 등이 실현되는 정도에 따른 각자의 주관적인 만족의 정도를 말하거나 마음에 흡족함 또는 모자람 없이 충분하고 넉넉함이라고 할 수 있다. 고객만족은 일정수준 이상으로 고객이 원하는 것을 찾아내어 고객의 만족조건을 최대한 보장하고 충족시켜주는 것을 의미하며, 고객이 만족하려면 우선 제품이나 서비스를 이용한 결과 만족할 만한 경험이 고객에 의해 지각되어야 하는데, 인식주체인 고객이 지각한 품질이 기대한 품질과 같거나 그 이상이 되면 고객만족에 이르게 된다[15]. 고객만족을 고객들의 욕구와 기대를 충족시키기 위하여 서비스 수행의 결과로부터 고객이 느끼는 전반적인 흡족함 또는 즐거움의 정도로 정의한다. 고객만족과 고객 불만족은 고객이 제품이나 서비스를 평가, 선택, 비교, 구매하는 과정에서 어느 정도 호의적이거나 비호의적 감정을 경험할 수 있느냐 하는 것이다[16]. 본 연구에서는 전통찻집에 대한 고객만족을 전통찻집 이용자 개인이 느끼는 기대감이나 욕구 등이 실현되는 정도에 따른 흡족함 또는 모자람이 없는 주관적인 만족 정도로 정의하고자 한다.

\section{3. 연구 설계 및 방법}

\section{1 연구 모형과 가설}

본 연구는 전통찻집 이용자가 전통차와 차문화를 누리는 과정에서의 고객경험, 정서적 반응, 고객가치 및 고객만족 간의 구조관계를 규명하는 데 그 목적이 있다. 이를 위해여 이종범(2007), 권진수·권용주(2012), 구동우(2015), 이경희·정갑연(2016), 선종갑(2018) 등의 다양한 선행연구를 바탕으로 전통찻집의 고객경험에 관한 이론적 배경을 기반으로 연구모형을 제안하고, 나아가 고객경험의 하위차원인 감각적 경험, 지적 경험, 행동적 경험, 정서적 경험으로 세분하여 이들 요인과 전통차와 전통찻집의 정서적 반응, 고객가치, 만족도 등으로 구성하여 변수들 간의 구조관계를 검증하고자 다음과 같이 연구모형과 연구가설을 설정하였다[17-21]. 


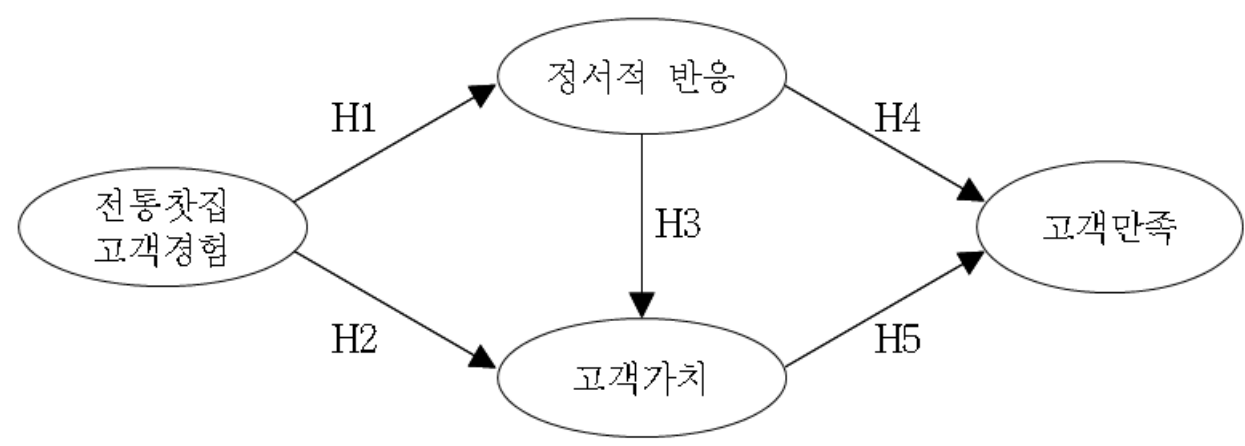

[그림 1] 연구모형

[Fig. 1] Research Model

가설 1: 전통찻집의 고객경험은 정서적 반응에 정 $(+)$ 의 영향을 미칠 것이다.

가설 2: 전통찻집의 고객경험은 고객가치에 정 $(+)$ 의 영향을 미칠 것이다.

가설 3: 전통찻집의 정서적 반응은 고객가치에 정 $(+)$ 의 영향을 칠 것이다.

가설 4: 전통찻집의 정서적 반응은 고객만족에 정 $(+)$ 의 영향을 미칠 것이다.

가설 5: 전통찻집의 고객가치는 고객만족에 정 $(+)$ 의 영향을 미칠 것이다.

\section{2 자료 수집 및 분석방법}

본 연구에서 설정한 연구가설의 검증에 활용된 기초자료의 수집을 위한 설문조사는 부산 지역에 거주하는 전통찻집의 이용 경험이 있는 소비자를 무작위로 추출하고, 이들을 대상으로 구조화된 설문지를 이용하여 진행하였다. 설문조사는 2019년 2월부터 4 월까지 3 개월간 실시하였으며, 총 350 부를 배부하여 최종적으로 296 부의 유효설문을 분석에 활용하였다. 수집된 자료는 SPSS 26.0을 이용하여 일반 현황분석을 위한 빈도분석과 측정변수의 신뢰도와 타당성분석을 실시하였으며, 변수의 집중 타당성과 판별 타당성 그리고 연구가설의 검증을 위하여 $\mathrm{AMOS} 26.0$ 을 활용하였다.

\section{4. 분석 결과}

\section{1. 표본의 특성}

본 연구를 위해 수집된 설문 응답자의 인구통계학적 특성 분석결과는 다음과 같다. 먼저, 응답자의 성별 현황은 전체 296명의 응답자 중 남성이 $42.9 \%(127$ 명), 여성이 $57.1 \%(169$ 명 $)$ 인 것으로 나타나 여성의 비중이 더 높은 것으로 나타났다. 둘째, 연령대는 20 대 $12.5 \%(37$ 명), 30 대 $12.8 \%(38$ 명 $), 40$ 대 23.6\%(70명), 50 대 $33.4 \%(99$ 명), 60 대 이상 $17.6 \%(52$ 명)로서 전반적으로 $40 \sim 50$ 대가 많은 것으로 나타났다. 셋째, 직업 현황에서는 회사원 및 공무원 $19.9 \%(59$ 명), 전문직 $16.6 \%$ (49명), 자영업 $23.3 \%(69$ 명), 전업주부 $22.0 \%(65$ 명), 학생 $13.9 \%(41$ 명), 기타 4.4\%(13명)로 자영업과 전업주부 순으로 응답자가 많은 것으로 나타났다. 넷째, 월평균 수입 현황은 100 만원미만 $17.6 \%(52$ 명), 100 만원200 만원미만 $\quad 14.2 \%(42$ 명), $\quad 200$ 만원-300만원미만 $\quad 17.6 \%(52$ 명), $\quad 300$ 만원-400만원미만 $14.9 \%$ (44명), 400 만원-500만원미만 20.6\%(61명), 500만원이상 $15.2 \%(45$ 명)로 나타났다. 


\section{2 측정변수의 신뢰성과 타당성 분석}

본 연구에서 설정한 각 구성개념에 대한 신뢰성과 타당성 검증을 위해 [표 1]에서 보는 바와 같이 신뢰성분석과 탐색적 요인분석을 실시하였으며, 모든 요인들의 신뢰성과 타당성이 확인되었다.

[표 1] 자료의 신뢰성과 타당성분석 결과

[Table 1] Result of Reliability and Validity Analysis

\begin{tabular}{ccccc}
\hline 변수명 & 항목 & Cronbach' a & eigen value & variance(\%) \\
\hline \multirow{2}{*}{ 전통찻집의 } & 지적 경험(5개 항목) & .897 & 8.248 & 51.553 \\
고객경험 & 행동적 경험(4개 항목) & .882 & 1.678 & 10.485 \\
& 정서적 경험(4개 항목) & .890 & 1.332 & 8.326 \\
& 감각적 경험(3개 항목) & .946 & 1.037 & 6.480 \\
\hline \multirow{2}{*}{ 정서적 반응 } & 감정반응(7개 항목) & .893 & 7.169 & 59.742 \\
& 정신적 반응(5개 항목) & .872 & 1.114 & 9.283 \\
\hline \multirow{2}{*}{ 고객가치 } & 경제적 가치(4개 항목) & .891 & 6.496 & 49.971 \\
& 서비스 가치(4개 항목) & .889 & 1.519 & 11.684 \\
& 매력 가치(5개 항목) & .802 & 1.118 & 8.600 \\
\hline \multirow{2}{*}{ 고객만족 } & 고객만족(3개 항목) & .954 & 4.359 & 72.657 \\
\hline
\end{tabular}

\section{3 확인적 요인분석}

본 연구에서는 다 항목을 이용한 각 측정항목에 대한 단일 차원성을 검정하기 위하여 확인적 요인분석을 실시하였다. 본 연구의 모형은 2 차 확인적 요인분석을 통해 측정 모형의 적합도를 검증하고, 이론변수들의 평균값을 사용하였다. 이 과정에서 수정지수를 이용하여 최적모형을 도출하기 위한 척도정제 과정을 거쳤으며, 이의 최종 결과는 다음의 [표 2]와 같다.

[표 2] 확인적 요인분석 결과

[Table 2] Result of Confirmatory Factor Analysis

\begin{tabular}{|c|c|c|c|c|c|c|}
\hline 개념변수 & 측정항목 & 표준적재치 & 표준오차 & t값 & $\begin{array}{c}\text { 복합신뢰도 } \\
\text { (CR) }\end{array}$ & $\begin{array}{c}\text { 분산추출지수 } \\
\text { (AVE) }\end{array}$ \\
\hline 고객경험 & $\begin{array}{l}\text { 감각적경험 } \\
\text { 지적경험 } \\
\text { 행동적경험 } \\
\text { 정서적경험 }\end{array}$ & $\begin{array}{l}.625 \\
.778 \\
.741 \\
.829\end{array}$ & $\begin{array}{c}.071 \\
.066 \\
- \\
.063\end{array}$ & $\begin{array}{c}10.701 \\
13.522 \\
- \\
14.466\end{array}$ & 897 & .687 \\
\hline 정서적반응 & $\begin{array}{l}\text { 감정반응 } \\
\text { 정신적반응 }\end{array}$ & $\begin{array}{l}.887 \\
.825\end{array}$ &. & $\begin{array}{c}- \\
18.060\end{array}$ & .930 & .870 \\
\hline 고객가치 & $\begin{array}{c}\text { 서비스가치 } \\
\text { 매력가치 } \\
\text { 경제적가치 }\end{array}$ & $\begin{array}{l}.662 \\
.793 \\
.772\end{array}$ & $\begin{array}{l}.068 \\
- \\
.061\end{array}$ & $\begin{array}{c}11.809 \\
- \\
14.237\end{array}$ & .875 & .701 \\
\hline
\end{tabular}




\begin{tabular}{r|c|c|c|c|c|c}
\hline \multirow{3}{*}{ 고객만족 } & 전반적만족 & .938 & .032 & 30.628 & & .973 \\
& 분위기만족 & .933 & .033 & 30.212 & - & .923 \\
& 서비스만족 & .933 & - & - & \\
\hline
\end{tabular}

확인적 요인분석 결과 적합도 지수 $x^{2}=71.863$ (d.f=45, $\mathrm{p}=.001$ ), $\mathrm{RMR}=.013, \mathrm{GFI}=.963$, $\mathrm{AGFI}=.936, \mathrm{NFI}=.975, \mathrm{RFI}=.975, \mathrm{CFI}=.990, \mathrm{RMSEA}=.044$ 등으로 나타나 모두 일반적인 추천 기준치를 충족시키고 있으며, 복합신뢰도(CR; Composite Reliability) 값이 추천치 0.7이상, 평균 분산추출지수(AVE; Average Variance Extracted) 값이 추천치 0.5이상인 것으로 나타나 집중타당도가 확보된 것으로 확인되었다.

\section{4 상관관계 분석}

각 요인들 간의 판별 타당성을 검증하기 위하여 각 요인들 간의 상관관계 분석을 실시하였으며, 그 결과는 다음의 [표 3]과 같다.

[표 3] 상관관계 분석 결과

[Table 3] Result of Corellation Analysis

\begin{tabular}{c|c|c|c|c}
\hline 구분 & 고객경험 & 정서적반응 & 고객가치 & 고객만족 \\
\hline 고객경험 & .644 & & & \\
\hline 정서적반응 & $.727^{* * *}$ & .701 & & \\
\hline 고객가치 & $.711^{* * *}$ & $.766^{* * *}$ & $\mathbf{. 8 7 0}$ & $\mathbf{9 2 3}$ \\
\hline 고객만족 & $.645^{* * *}$ & $.665^{* * *}$ & $.623^{* * *}$ & \\
\hline
\end{tabular}

대각선의 값은 평균분산추출지수(AVE) 값임, $* * * \mathrm{p}<.01$

변수들 간의 관련성 분석을 위하여 변수사이의 상관 또는 공분산 계산에 가장 폭 넓게 사용되는 상관계수로서 $\mathrm{AMOS}$ 분석결과를 활용하였다. 분석결과 표에서 보는 바와 같이 대각선의 분산추출지수(AVE) 값의 제곱근 값과 비교하여 상관계수 값이 큰 값이 발견되지 않았다. 따라서 본 결과를 기준으로 볼 때 판별 타당성이 확보된 것으로 볼 수 있다.

\section{5 연구가설 검증결과}

본 연구는 전통찻집의 고객경험, 정서적 반응, 고객가치 및 고객만족 간의 인과관계를 규명하는 것으로, 각 연구 단위들 간의 전체적 구조모형을 검증한 결과 및 가설검증 결과는 다음의 [표 4], [그림 2]와 같다.

가설검증 결과를 구체적으로 살펴보면, 먼저 전통찻집에 대한 고객경험이 정서적 반응에 어떠한 영향을 미치는가를 알아보기 위한 검증 결과, 표준화계수는 .792, t값은 $12.788(\mathrm{p}=.000)$ 로서 유의수준 .01 에서 통계적으로 유의한 것으로 나타나 가설 1 은 채택되었다. 또한 경로계수 값이 양 $(+)$ 의 값을 갖는 것으로 나타나 전통찻집의 
고객경험에 대한 긍정적 평가가 정서적 반응에 대해 유의한 정(+)의 영향을 미치고 있음을 확인하였다.

[표 4] 연구가설 검증결과

[Table 4] Result of Hypothesis Test

\begin{tabular}{|c|c|c|c|c|c|c|c|c|c|}
\hline 가설 & & 경로 & & 모수추정치 & 표준화계수 & S. E. & $\mathrm{t}$ & $\mathrm{p}$ & 검증결과 \\
\hline h1 & 고객경험 & & 정서적 반응 & .863 & .792 & .067 & 12.788 & $.000 * * *$ & 채택 \\
\hline h2 & 고객경험 & $\rightarrow$ & 고객가치 & .638 & .596 & .098 & 6.512 & $.000^{* * *}$ & 채택 \\
\hline h3 & 정서적 반응 & $\rightarrow$ & 고객가치 & .278 & .282 & .089 & 3.123 & $.001 * * *$ & 채택 \\
\hline h4 & 정서적 반응 & $\rightarrow$ & 고객만족 & .335 & .310 & .099 & 3.370 & $.000^{* * *}$ & 채택 \\
\hline h5 & 고객가치 & $\rightarrow$ & 고객만족 & .439 & .399 & .101 & 4.330 & $.000^{* * *}$ & 채택 \\
\hline
\end{tabular}

$x^{2}=62.849$ (d.f. $\left.=46, \mathrm{p}=.050\right), x^{2} /$ d.f. $=1.366, \mathrm{RMR}=.011, \mathrm{GFI}=.968, \mathrm{AGFI}=.946, \mathrm{NFI}=.979, \mathrm{RFI}=.970, \mathrm{CFI}=.994, \mathrm{RMSEA}=.035$ $* * * \mathrm{p}<.01$

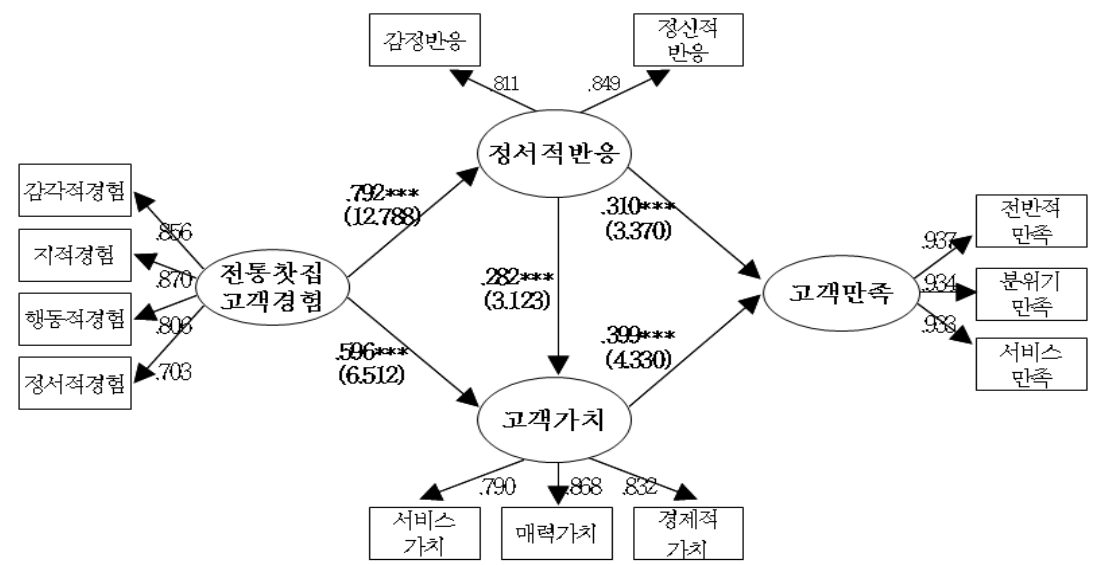

[그림 2] 연구가설 검증결과

[Fig. 2] Result of Hypothesis Test

둘째, 전통찻집의 고객경험이 고객가치에 미치는 영향에 대한 가설2를 검증한 결과, 표준화계수는 $.596, \mathrm{t}$ 값은 $6.512(\mathrm{p}=.000)$ 로서 유의수준 .01 에서 통계적으로 유의한 것으로 나타나 가설2도 채택되었다. 또한 경로 계수값이 양 $(+)$ 의 값을 갖는 것으로 나타나 전통찻집에 대한 고객경험의 긍정적 평가가 고객가치도 향상시킨다는 결과를 확인하였다. 셋째, 정서적 반응이 고객가치에 미치는 영향에 대한 가설 3 을 검증한 결과, 표준화계수는 $.282, \mathrm{t}$ 값은 $3.123(\mathrm{p}=.001)$ 로서 유의수준 .01에서 통계적으로 유의한 것으로 나타나 가설3도 채택되었다. 또한 경로계수 값이 양 $(+)$ 의 값을 갖는 것으로 나타나 정서적 반응이 긍정적일수록 고객가치는 높아진다는 결과를 확인하였다. 넷째, 정서적 반응이 고객만족에 어떠한 영향을 미치는가를 알아보기 위한 가설4를 검증한 결과, 표준계수는 $.310, \mathrm{t}$ 값은 $3.370(\mathrm{p}=.000)$ 로서 유의수준 .01 에서 통계적으로 유의한 것으로 나타나 가설4도 채택되었다. 또한 경로계수 값이 양 $(+)$ 의 값을 갖는 것으로 나타나 전통찻집에 대한 정서적 반응이 만족에 긍정적 영향을 미치고 있음을 확인하였다. 끝으로, 고객가치가 고객만족에 미치는 영향에 대한 가설5를 검증한 결과, 
표준화계수 .399 , t값은 $4.330(\mathrm{p}=.000)$ 로서 유의수준 .01에서 통계적으로 유의한 것으로 나타나 가설5도 채택되었다. 또한 경로계수 값이 양 $(+)$ 의 값을 갖는 것으로 나타나 고객가치가 높을수록 만족도가 높아진다는 결과를 확인하였다.

\section{5. 결론}

본 연구는 전통차와 전통찻집의 활성화 방안을 제시하고자 하는 목적으로 기존의 선행연구의 문헌을 고찰하고, 고객경험을 통해 경험변인들 사이에서 정서적 반응과 고객가치가 고객만족의 매개 역할을 하는지를 실증적으로 검증하였다. 본 연구에서는 전통찻집에서의 고객경험을 측정하는데 Brakus et al.(2009)의 4가지 경험차원을 척도로 이용하여 신뢰성과 타당성을 확인하였다. 실증분석을 통해 고객경험의 4가지 경험차원이 정서적 반응, 고객가치 및 고객만족도에 미치는 영향관계가 모두 유의함을 검증하였다. 따라서 이들의 관계를 실증분석을 통해 도출된 결과를 바탕으로 향후 전통찻집의 운영 및 마케팅 활동에서 중점적으로 다뤼야 할 전략적 시사점을 제시하면 다음과 같다. 먼저 전통찻집의 고객경험이 정서적 반응 및 고객가치에 미치는 영향의 중요성 정도를 비교한 결과 지적 경험(.870) > 감각적 경험(.856) > 행동적 경험(.806) > 정서적 경험(.703) 등의 순으로 영향관계가 큰 것으로 나타났다. 따라서 전통찻집의 고객경험이 정서적 반응 및 고객가치를 긍정적으로 향상하기 위해서는 전통찻집의 고객경험 요인인 지적, 감각적 경험 요인에 대하여 우선적으로 지속적인 노력을 기울여야 할 필요가 있다고 본다. 둘째, 전통찻집에 대한 정서적 반응이 고객가치와 고객만족에 미치는 영향의 중요성 정도를 분석한 결과 정신적 반응(.849) > 감정반응(.811) 등의 순으로 영향관계가 큰 것으로 분석되었다. 따라서 방문고객의 가치를 극대화하기 위해서는 정서적 반응 요인 중 정신적 반응과 감정반응을 강화하는 노력이 선행되어야 하며, 나아가 고객만족을 높일 수 있는 전략적 접근이 필요하다. 셋째, 전통찻집의 고객가치가 고객만족에 미치는 영향관계를 비교한 결과 매력가치(.868) > 경제적 가치(.832) > 서비스가치(.790) 등의 순으로 영향관계가 큰 것으로 나타났다. 따라서 전통찻집의 고객가치가 고객만족도를 높이기 위해서는 우선적으로 매력가치 요인을 극대화하여 고객만족을 강화할 필요가 있다. 따라서 전통찻집의 방문고객의 고객만족 및 지속적인 이용도를 높이기 위해서는 방문고객에 대한 사후관리 및 만족요인들을 강조하는 전략적 접근이 요구된다고 할 수 있다. 이러한 결과는 구성 요인들의 상대적 중요성 등을 확인함으로서 향후 전통찻집의 활성화에 있어 실무적인 가능성을 확인했다는데 그 의의가 있다고 할 수 있다. 그러나 본 연구는 표본선정과 자료수집에 있어서 공간적, 시간적 제약으로 인해 모집단의 특성을 충분히 반영하지 못하였다. 표본대상이 부산지역 40-50대 전통찻집 이용경험이 있는 소비자가 다수를 차지하고 있어 연구결과의 일반화에 한계가 있을 수 있다. 따라서 향후 표본대상의 범위와 연령층을 확대하고, 관련 특성 요인 등을 다양화하는 연구가 진행될 필요가 있다고 본다.

\section{References}

[1] Lee Su Jin, A Study on the Method of Revitalizing Gwangju Asian Tea Culture Festival, Graduate School of Chosun University, Master's thesis, pp. 27-53, (2012) 
[2] Lee Su Min, A Study on the Korean Education of Tea Culture: Focusing on the Educational Institutions for Experts, Graduate School of Keimyung University, Master's thesis, pp. 8-31, (2008)

[3] Lee Hae Sook, A Study on Improvement Method for Popularization of Korean Traditional Tea Culture, (2016), Graduate School of Dongguk University, Master's thesis, pp.5-23, (2016)

[4] C. Meyer, A. Schwager, Understanding Customer Experience, Harvard Business Review, (2007), Vol.85, No.2, pp.116126.

[5] So Eun Jeong, The Effect of Customer Experience on Emotional Responses, Satisfaction and Behavior Intention at Coffee Shop : Focusing on the Moderating Effect of Involvement and Consumption Values, Graduate School of Kyung Hee University, Master's thesis, pp.13-23, (2018)

[6] J. J. Brakus, B. H. Schmitt, L. Zarantonello, Brand Experience; What is it? How is it measured? Does it affect loyalty?, Journal of Marketing, (2009), Vol.73, No.3, pp.52-68, DOI: 10.1509/jmkg.73.3.52

[7] L. Zarantonello, B. H. Schmitt, Using the Brand Experience Scale to Profile Consumers and Predict Consumer Behaviour, Journal of Brand Management, (2010), Vol.17, pp.532-540, DOI: https://doi.org/10.1057/bm.2010.4

[8] R. Plutchik, Emotion: A Psychoevaluationary Synthesis, Harper \& Row, (1980)

[9] M. C. Burke, J. A. Edell, The Impact of Feelings on Ad-based Affect and Cognition, Journal of Marketing Research, (1989), Vol.26, No.1, pp.69-83, DOI: 10.2307/3172670

[10] J. Kim, Y. Baek, Y. H. Choi, The Structural Effects of Metaphor-elicited Cognitive and Affective Elaboration Levels on Attitude toward the Advertising, Journal of Advertising, (2012), Vol.41, No.2, pp.77-96, DOI: 10.2753/JOA00913367410206

[11] B. T. Gale, R. C. Wood, Managing Customer Value: creating quality and service that customers can see, The Free Press, pp.23-50, (1994)

[12] D. C. Bojanic, Consumer Perceptions of Price, Value and Satisfaction in the Hotel Industry: an Exploratory Study, Journal of Hospitality and Leisure Marketing, (1996), Vol.4, No.1, pp.5-22, DOI: 10.1300/J150V04N01_02

[13] R. B. Woodruff, Customer Value: The Next Source forCompetitive Advantage, Journal of the Academy of Marketing Science, (1997), Vol.25, pp.139-153, DOI: https://doi.org/10.1007/BF02894350

[14] V. A. Zeithaml, Consumer Perceptions of Price, Quality, and Value: A Means-End Model and Synthesis of Evidence, Journal of Marketing, (1988), Vol.52, No.3, pp.2-22, DOI: https://doi.org/10.2307/1251446

[15] Lee Sun Ryong, Modern Quality Management, 3rd edition, Beobmunsa, (2016)

[16] R. L. Oliver, R. L., Cognitive, Affective, and Attribute Bases of the Satisfaction Response, Journal of Consumer Research, (1993), Vol.20, No.3, pp.418-430, DOI: https://doi.org/10.1086/209358

[17] Lee Jong Byum, A Research about the Consumer's Rational or Emotional Responses of the Advertising Exposure, Graduate School of Cheong Ju University, Master's thesis, pp. 24-41, (2007)

[18] Kwon Jin Soo, Yong Ju Kwon, A Study on the Influence of Value Recognized by Guest House Customers on the Emotional Reaction and the Intention of Revisiting, Korean Journal of Hospitality and Tourism, (2012), Vol.21, No.5, pp.105-120, UCI: G704-001024.2012.21.5.010

[19] Koo Dong-Woo, The Effect of Family Restaurant Customers' Experiential Value on Emotion, Consumer-Brand Relationship and Brand Loyalty, Journal of Tourism Services Research, (2015), Vol.12, No.2, pp.55-80.

[20] Lee Kyung Hee, Gap Yeon Jeong, A Study on the Effect of Overall Brand Experiences on Emotional Consumption Value and Brand Identification: Focused on Color Cosmetics Brands, Journal of Product Research, (2016), Vol.34, No.3, pp.41-53, DOI: 10.36345/kacst.2016.34.3.005

[21] Sun Jong-Gab, A Study on the Effect of Service Quality of Five-Star Hotel on Customer Value, Customer Satisfaction, and Repurchase Intention, Kournal of Tourism and Leisure Research, (2018), Vol.30, No.10, pp.133-147. 